\title{
Regional characteristics and evolution of the form of traditional courtyard houses in the coastal fishing village, Hongmao Harbour in Kaohsiung
}

\author{
Y.-T. Chang \\ Department of Architectural Engineering, Ceng Shiu University, Taiwan \\ National Cheng Kung University, Taiwan
}

\begin{abstract}
The courtyard house is the major construction form of the traditional folk residence in Taiwan. All the settlements, whether in the mountain area, flatland or coastal area, adopt this pattern. The reason why courtyard house has become the first choice of the form of traditional folk residence is that its spatial form satisfies the expectations for good living space and for tight relationships between family groups based on the Chinese cultural concept. However, although the construction of courtyard house has its basic spatial organization, the difference in its geographical location, climatic condition, industrial form, spatial layout, material use and way of construction may create the so-called regional characteristics. In Taiwan the courtyard houses of agricultural villages are obviously different from the courtyard houses of coastal fishing villages because of the difference in their industries and geographical environments. The effects of nature and the human environment are fully reflected in the form of courtyard houses. Taking the settlement of Hongmao Harbour as the spatial area, this paper employs the collection of archives, investigation of substantive historical material and interviews to analyze the construction form and methods of the courtyard house. Through analysis, this paper presents the regional characteristics of the traditional courtyard house and the evolution of its form, investigates the changed and unchanged in the development of traditional folk residence, proposes explanation for the phenomenon that courtyard house finally no longer become the form of folk residence of Hongmao Harbour, and clarifies the relationship among the cultural concepts, realistic conditions and spatial form of folk residences.
\end{abstract}

Keywords: courtyard house, regional characteristics, column legs, woven bamboo frame, load-bearing wall structure. 


\section{Introduction}

Courtyard house is the major construction form of the traditional folk residence in Taiwan. All the settlements, no matter in the mountain area, flatland or coastal area, adopt this pattern. The reason for courtyard house to become the first choice of the form of traditional folk residence is that its spatial form satisfies the expectations for good living space and for tight relationship between family groups based on the Chinese cultural concept. However, although the construction of courtyard house has its basic spatial organization, the difference in its geographical location, climatic condition, industrial form, spatial layout, material use and construction way may create the so-called regional characteristics. In Taiwan the courtyard houses of agricultural villages are obviously different from the courtyard houses of coastal fishing villages because of the difference in their industries and geographical environments. It fully reflects the effects of the nature and the human environment on the form of courtyard houses.

Hongmao Harbour was situated at the southwestern part of Kaohsiung. During the Tseng Cheng-kung period in Ming Dynasty, there were residents migrating to Hongmao Harbour and settling down here. It was a typical settlement of the Chinese fishing village. The settlement was situated on a sandbank running in northwest-southeast direction, with the south-north length at 3,000 metres and the east-west width at only 100 metres. Since its western side is close to Taiwan Strait, whenever the weather was bad, storms and waves from the western side would attack the settlement. Therefore, as the construction of settlement was restricted by the such conditions as the moisture proof needs, economic power and difficult acquisition of material, the residence had to be made of regional materials, mainly the bamboo frames and laogu rocks. This was just for satisfying the construction needs and for being restricted by the natural environment. After the Second World War, the fishing industry of Hongmao Harbour became prosperous, and the growth of population was rapid accordingly. The original construction of courtyard house was under the limitation of land. In order to meet the need of spatial growth, there appeared the phenomenon of vertical extension. The process of development was very rich and complete. After the 1960's, under the original land inheritance system, the land of Hongmao Harbour was continuously sub-divided during the "division of family property." In addition, owing to the development and change of cultural concepts, new courtyard house was no longer constructed. With the successive division of family property and the construction of houses (commonly called "small houses" at that time), the original courtyard houses were demolished one after another. Gradually, the courtyard houses of Hongmao Harbour went into history. In 1968 Hongmao Harbour was incorporated in Linhai Industrial District, and any further construction of house was prohibited. From then on, the style and features of the settlement were consolidated. Today the lines of settlement and the form of buildings are generally retaining their old look. Currently, bamboo-framed and laogu-rock-structured folk residence can still be found in quite a lot of settlements. These buildings loyally record the 
development and the past history of the sandbank fishing village. The process of its development and evolution is thus preserved, leaving the best evidence for the development process of folk residence.

Taking the settlement of Hongmao Harbour as the spatial area, the paper employs the collection of archives, investigation of substantive historical materials and interviews to analyze the construction form and methods of courtyard house. Through the analysis, the paper presents the regional characteristics of the traditional courtyard house and the evolution of its form, investigates the changed and unchanged in the development of traditional folk residence, proposes explanation for the phenomenon that courtyard house finally no longer become the form of folk residence of Hongmao Harbour, and clarifies the relationship among the cultural concepts, realistic conditions and spatial form of folk residence. In the discussion of construction methods, the paper's investigation of the construction ways and techniques of houses is not only based on the substantive historical materials collected from the field surveys, but also added with the verbal historical materials supplied by the construction masters. As to the land rights that belong to the information of transfer, they are based on the verbal historical materials supplied by the owners of houses and the cadastral information provided by Cianjhen Land Administration Affairs Office of Kaohsiung City.

\section{Analysis of the traditional courtyard house and its formation}

\subsection{Outline of the traditional courtyard house}

Based on the patterns, the traditional courtyard houses of Taiwan are divided into four types, including one dragon, single stretched arm, three-sided courtyard house and four-sided courtyard house. The plane figure of one dragon appears in the shape of "一." Single stretched arm is on the foundation of one dragon, with its left side or right side constructed with a stretched arm. Thus, the plane figure appears in " $\urcorner$ " or " $\Gamma$ " shape. The three-sided courtyard house has its left side and right side both constructed with a stretched arm. Its plane figure appears in a " $\square$ " shape. Adding a front side to the three-sided courtyard house, the foursided courtyard house has its plane figure appeared in a " $\square$ " shape. Among the four types, one dragon and single stretched arm both adopt the transitional way of three-sided courtyard house.

The reason for courtyard house to become the first choice of the form of traditional folk residence is that its spatial form satisfies the expectations for good living space and tight relationship between family groups based on the Chinese cultural concept. It refers that in the residence a harmonious relationship should be established with the natural environment the residence is situated at, and with the people living in the residence. Of the nature, the traditional Chinese culture uses the concept of "chi" to interpret the creation and development of life. In the nature, there exist different kinds of air fields presented in the form of "cave." A good cave can bring happiness to the people 
living inside. On the contrary, the people will get disastrous damage. The air field formed by a good cave can concentrate the air in the cave. Under the property that "chi would be dispersed by wind and stopped by water," in front of an air field that can "hide wind and absorb chi," there must be water to "stop the chi," and sand piled up by the left and right sides to "hide the wind." Therefore, the $\Pi$-shaped layout and $\square$-shaped layout in traditional courtyard houses as well as the configuration of having hills behind and sea in front could exactly meet the need of good chi field for living, and accomplish the pursuit for a happy life. Over the construction of a harmonious relationship among people, the human relationship in a folk residence is the kinship relationship in a family, taking "respects for the relatives" and "proper order between the junior and the senior" as the standard of value. In a courtyard house, the bright bay of large room is designed as the hall for worshipping the ancestors and gods. The rooms by the two sides are arranged to have the rooms of the elder members of the family. The rest of the family members are distributed to the left and right stretched arms. The positioning of a person in a family is based on the person's location, spatial height and land height, presenting the concept of "proper order between the junior and the senior," and satisfying the need of community relationship in the traditional culture. Therefore, wherever there is Chinese culture, it is common to find the phenomenon of taking courtyard house as the major form of folk residence.

\subsection{Outline of the construction of folk residence in the coastal fishing village in Kaohsiung area}

Hongmao Harbour is located at Haishan, which is at the southwestern side of Kaohsiung in the southern part of Taiwan. Hongmao Harbour is under the jurisdiction of Kaohsiung City. Its southern side links to Linyuan Village, Kaohsiung County; its northern side connects with Jhongjhou and Cijin; its northern side is next to Zuoying, Nanzi, and also Ziguan, Mituo, Yong-an, Jiading, and so on of Kaohsiung City. The traditional folk residences currently existed in the coastal fishing village in these areas are mainly the three-sided courtyard houses. The size of a large room is sufficient for accommodating three or five open bays, and the size of a stretched arm is available for building one to three open bays. The forms of structure include woven bamboo frame, woven wooden frame, load-bearing wall in laogu stone structure, load-bearing wall in brick-stone mixed structure, load-bearing wall in brick structure, and so on. Regarding the growth of courtyard house, these settlements were generally grown in a form combining with the additionally built courtyard houses. A few of them appear in the growth cases of the protective dragon pattern, with outer protective dragons additionally constructed by the two sides. In comparison with those of Hongmao Harbour, its space and structural form have no great difference from those of Hongmao Harbour. Nevertheless, regarding the ways of growth of courtyard houses, there appeared a unique growth mode to the courtyard houses in Hongmao Harbour due to the geographic conditions and the inheritance system. 


\subsection{Courtyard houses of Hongmao Harbour}

Because of the prohibition of construction, the forms of buildings currently existing in the settlements of Hongmao Harbour are generally retaining their old look. Except the temporary buildings of corrugated houses additionally built to meet the residential needs after the prohibition of construction, there are not many great changes found. Thus, the settlements have preserved many representative buildings full of distinctive features. As observed from the current situation, the residential buildings in Hongmao Harbour cover such types as courtyard houses, long narrow houses, street houses, and so on (Figure 1). But after their development has been carefully studied, it is found that the forms and features of these diversified types are in fact formed with the gradual renewal of construction technology, renewal of materials and formation of new land by land reclamation. Therefore, this paper takes the buildings of courtyard houses as the research targets, and deeply investigates their forms and changes.

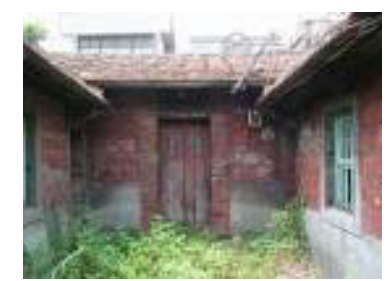

Three-sided courtyard house

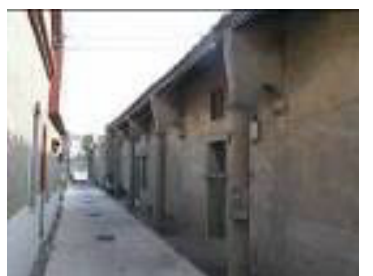

Protective dragon house

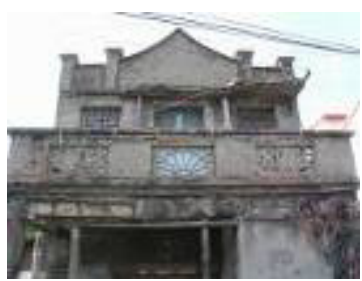

Street house

Figure 1: Types of the residential buildings in Hongmao Harbour: categorization according to the form of building.

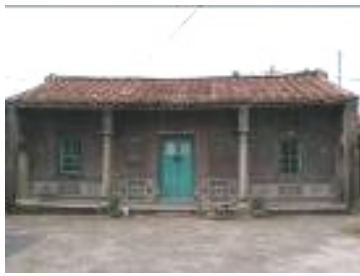

One dragon

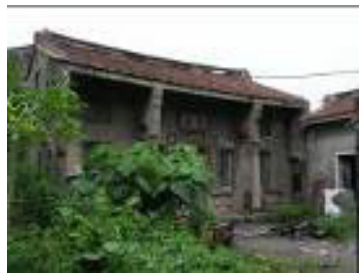

Single stretched arm Three-sided courtyard house

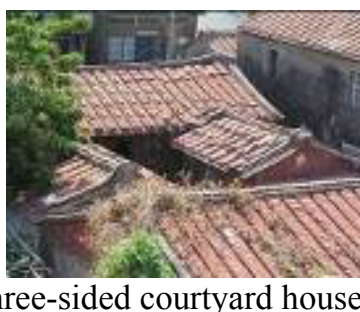

Figure 2: Courtyard house buildings in Hongmao Harbour.

The types of the courtyard houses in Hongmao Harbour include one dragon, single stretched arm and three-sided courtyard house (Figure 2). Restricted by land area and economic situation, no case of four-sided courtyard house is found. To accommodate the relief of Haishan (in northwest-southeast direction), most of the courtyard houses are situated in southwestern direction and facing the northeast eastern direction, with the width of the façade accommodating three or five open bays. 
The plane figure of a courtyard house is in " $\Pi$ "shape. It is composed of "large rooms" (or commonly called "front bodies") and "chambers" (or commonly called "stretched arms"). The vacant land encircled by large rooms and chambers is called "doorstep square" (Figure 3). It is a major space for people to carry out outdoor activities. In the early days, courtyard house was in the one-storey form. After the 1950's there appeared the 11/2-storey and the 2storey courtyard houses, which were the buildings in Hongmao Harbour full of distinctive features.
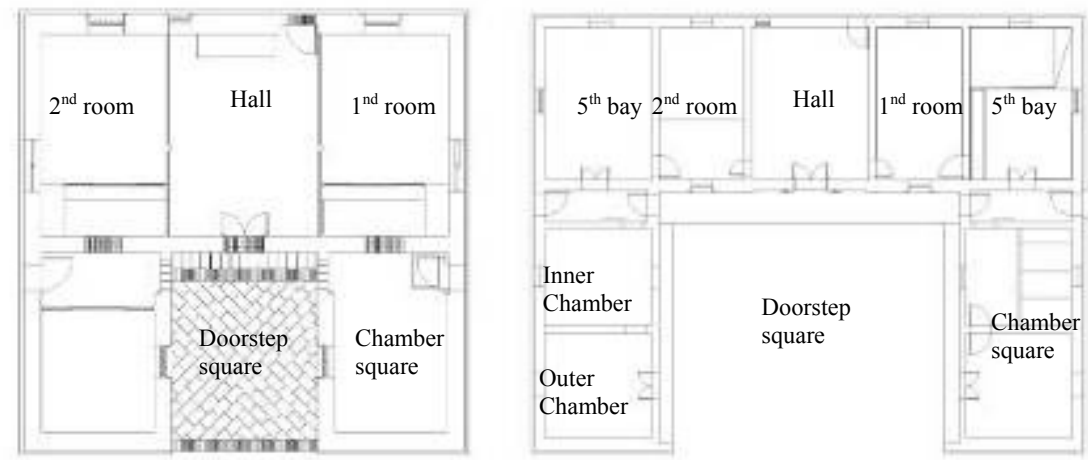

Figure 3: Name chart of the space of courtyard house buildings in Hongmao Harbour.
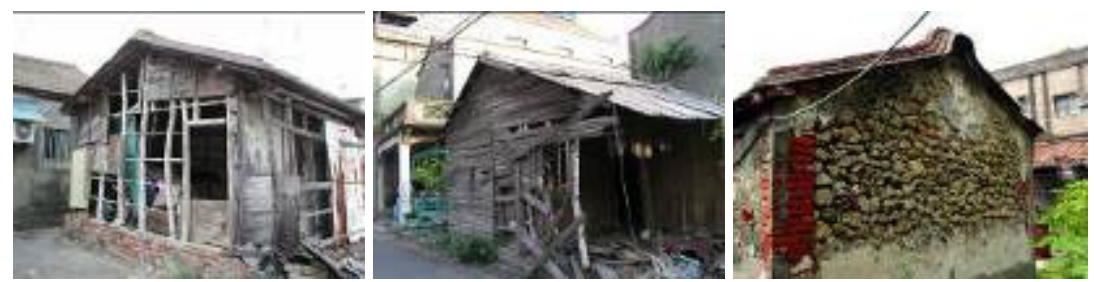

Constructed by bamboos Constructed by bamboos Constructed by Laogu rocks

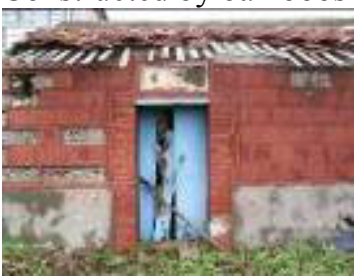

Constructed by bricks

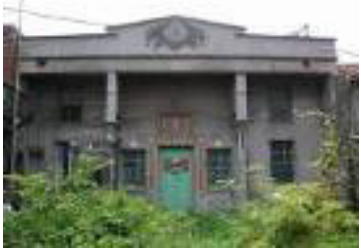

Constructed by bricks

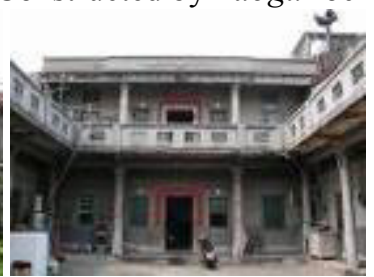

Constructed by strengthened bricks

Figure 4: Types of buildings in Hongmao Harbour: categorized according to styles.

Of the structural form, the traditional courtyard houses of Hongmao Harbour are divided into bamboo frame, $\operatorname{lag} u$ stone structure, brick and stone mixed structure, brick structure, strengthened brick structure, etc. (Figure 4). Not only 
the diversity of structural form is presented, its changes are also shown as follows.

\subsection{Bamboo frame}

The bamboo-framed building is commonly called "bamboo house," "bamboo pillared house," or "column legged house." It is commonly called "column legs" in Hongmao Harbour. It is easy to acquire the material, and is simple to build the frame. Its structure and system are simple, with simple structural principles, simple technical standards and tools, normal engineering methods, and easy application of labour, so that users can build it up themselves in a very short construction period.

The bamboo-framed buildings of Hongmao Harbour are mainly the 3-bay-up ones with simply pattern. The roof is hanged hill roof, double-slope roof. The roof is mainly covered by cogongrass or sugar cane leaves. Part of the roof cases are found to be covered by plate tiles. According to the kinds and diameter of bamboos, the frame is "woven" to be a framed shelf, on which is covered with pillars and roof face. There are three ways of building the walls. The first way is the making of bamboo-framed mud wall, which uses bamboo or silvergrass rod to be the framework, with its surface paved with mud. The second way is the use of the bark of China fir, and its construction way is similar to that of rainproof board. The third way is the use of wooden plate, and its construction way is the same as using the bark of China fir. The making of bamboo-framed mud wall was frequently used in the early days. But the making process was more complicated, a lot of time was required, and the wall could be corroded due to humidity. Therefore, it was gradually replaced by the ways of using the bark of China fir or wooden plates because the making process is easier. The base foundation is made by building the frame with laogu stones. The middle part is solidified by ramming the earth. Cobblestones or rocks are always placed at the foot base to support the columns.

As to the use of materials, Bambusa stenostachya Hackel, a kind of very thick bamboo is used as the erected column. Phyllostachys makinoi Hayata, a kind of thin bamboo, is used for building the horizontal parts, whereas the straighter Bambusa stenostachya Hackel is used for building the vertical pillars. Since no bamboo was grown in Hongmao Harbour, the material of bamboo is mostly transported from the place nearby, Cishan area in Kaohsiung County.

The way of forming the structure is by weaving. Many woven parts are assembled. The weaving work is very easy because it does not take much effort to dig the hollowed bamboo. As for the working procedures, first of all, the number of bamboos for the erected columns has to be determined according to the depth of the building and the water to be added on the roof. Secondly, the position for weaving has to be determined. Try to arrange the positions on the ground first. Then drill holes on the erected columns and leave marks of the size. After that, carry out weaving and the assembling of the woven parts. Since the holes are dug in advance during the weaving of walls, it takes only one working day by a chief labourer and an assistant. The process is very timesaving. The large piece of wall can be pre-woven on the ground. After 
assembling, only two to three persons are required to pull it up and put it at the right position. Then the procedures like the positioning of bamboo pillars, installation of doors and windows, and the paving of roof, and so on, can be carried out.

Only requiring sawing, digging, peeling and excavation, the engineering method of bamboo frame is simple and easy to be completed, with no need of any special techniques. In addition, the construction period for a building is as short as about 20 days, and the cost of material is not high. Moreover, the bamboo framed building has good ventilation. Even if the sea waves flood into the house, the main structure will not be damaged. In this case, only the mud on the wall may be lost for being washed away by the sea water. The bare bamboo frame may be left, so there is no danger of collapse of wall and no hazard to human lives. The structure also enjoys the advantage of easy moving. Therefore, in terms of construction, use of labour, economicality, intelligence, techniques, matching with the time of industries, and the mingling with traditional folk customs, they all meet the needs of general residents. Therefore, bamboo frame became the main construction form of folk residence in Hongmao Harbour in the early days.

\subsection{Laogu stone structure}

Laogu stone structure mainly uses the coral reef rocks collected from the neighbouring area, Fengbitou, with mud and soil adhered to them. The structure of this wall body adopts a random paving way of laogu stones, which are supported by pillars and roof. The rock materials for the corners of wall body are trimmed by axe, or partially changed to be piled up by red bricks. The roof is the hard-hill double-slope roof. The roofing materials are the red plate tiles, with one face-up tile and one face-down tile connecting with one another. Without any decoration, the ridge of roof is plain. The body of house is in the form of "chujici," supporting the eaves. Part of the cases use bamboo as the body material. Besides, residues of bamboo frame are also found in the wall body. It tells us the development from the original bamboo frame to the laogu stone structure.

\subsection{Brick-stone mixed structure}

Brick-stone mixed structure is mainly found in the 3-bay-up or 5-bay-up courtyard houses. It generally appeared when the economy turned better and the living place was stable. The exquisiteness and life cycle of this structure is higher than the bamboo framed building. Similar to laogu stone structure, the structure has pillars inside the wall and is for the load-bearing wall, but the volume of brick materials and the area are larger than the laogu stone structure. The façade wall and the gables by the two sides of hallway wall are mainly built by the brick materials. The brick laying way of running bond has its distinctive features. In Hongmao Harbour the running bond is a mixed structure of red bricks and laogu stones. The red bricks are laid in box form, and its inside is filled with $\operatorname{lag} u$ stones. The exposed red bricks form the beautiful pattern of wall surface. 
The foundation of the brick-stone mixed courtyard house uses laogu stones to build the frame. The middle part is solidified by ramming the earth. Because of the frequent flood disasters, bulkhead is generally built at the foundation of wall. On the one hand, it has the function of preventing flood; on the other, it has the effect of beautifying the environment. In the early days the paving materials on land surface were mainly the rammed earth. Later on, the cement and bricks were gradually used. The body of the house are generally in two forms, "chujici" and "chubuci." In the earlier years it was mainly the "chujici" form. "Chubuci" did not appear until it was found in the large room built after the 1940's. The roof is in the form of hard hill, which has the patterns of doubleslop roof and flat roof. The materials of double-slope roof are the red plate tiles, with one face-up tile and one face-down tile connecting with one another. Flat roof is also called brick plane, which is laid by chih bricks and chih-er bricks, or made flat by spreading the cement. The roof top can be offered for sun drying the agricultural products or fishing products. Between two roof slopes is the juncture called "middle ridge" or "ridge." There are two ways of building the middle ridge: large ridge and small ridge. The large ridge is decorated with willow bricks or colourful porcelain bricks. In some cases, the decorating methods of mosaic and mud moulding are found. There are two forms of ridge head: one is "horse ridge" and the other is the simplified geometric ridge head called "wajhen".

\section{Growth of the traditional courtyard houses of Hongmao Harbour and the evolution of their forms}

\subsection{Spatial growth of courtyard house}

Normally, the construction of a traditional courtyard house in Hongmao Harbour could not be completed for once. With the growth and development of family size, organic growth mode began to appear. The construction work was always completed in different phases at different periods of time. For the construction procedures, large room (3-bay-up or 5-bay-up) was generally constructed first. After that, 5-lay-up and chamber were built. Or large room and left chamber were constructed first, and then right chamber later. The construction was extended according to the idea of sequence. Therefore, after accumulation of the constructed parts of the courtyard house at different periods of time, asymmetrical forms and features completed at different periods of time thus appeared . Furthermore, with the continuous increase of the pressure of population growth and the inadequate use of space, some family members had their family properties divided and additional courtyard houses constructed; or had protective dragon room additionally constructed in front of the courtyard house. Therefore, the mode of spatial growth of courtyard house is closely related to the economic power of the house owner, and to the growth of population. In order to meet the need of spatial growth, in addition to the complete form of a courtyard house, the wall surface outside the folk residence was frequently found to have brick gaps and door holes preserved for subsequent expansion and construction of rooms in the later days. 


\subsection{Evolution of the space and structure of courtyard house}

With the development of times background, construction materials and construction technology, the forms and structures of courtyard houses of Hongmao Harbour went through evolution for several stages. Among them, some were the phenomena of courtyard houses commonly seen in the coastal fishing village in Southern Taiwan, but some were resulted from the evolution of the special natural, human and cultural environments of Hongmao Harbour. According to the space and construction forms, the paper explores the evolution of courtyard houses in Hongmao Harbour.

\subsubsection{Evolution of the space of courtyard house}

In the early days the traditional courtyard houses of Hongmao Harbour were in one-storey form. Later on, owing to the growth of population, difficult acquisition of land and the inheritance and division of land, the horizontal expansion of courtyard house buildings was restricted. With the help of material change, vertical expansion was achieved to grasp more space, developing the one-and-half-story and two-storey courtyard houses, and forming the distinctive features of the settlements in Hongmao Harbour.

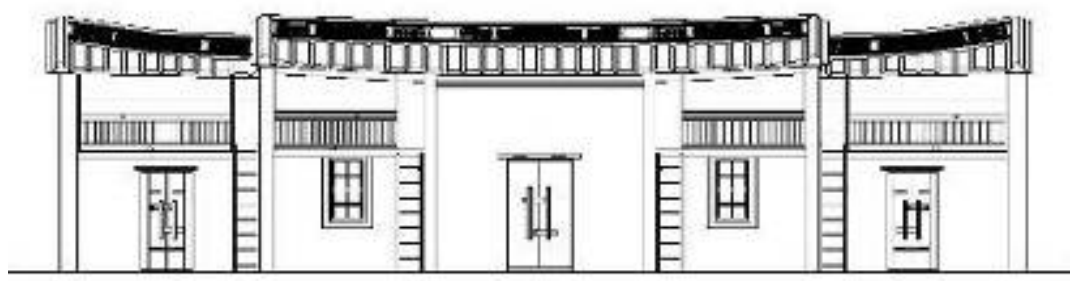

Figure 5: Half storey.

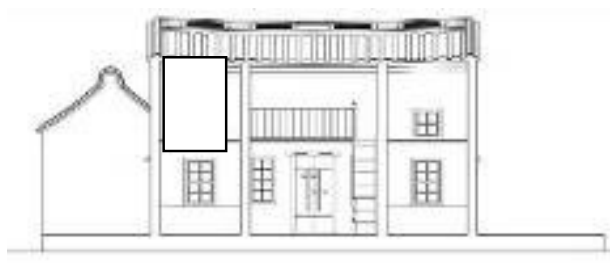

Figure 6: Vault.

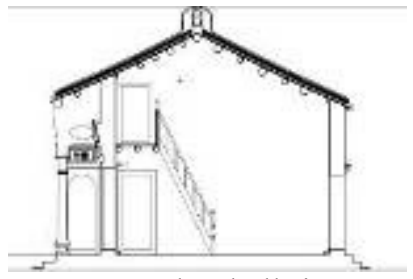

Figure 7: The hall is constructed with staircase and half storey for reaching left and right rooms.
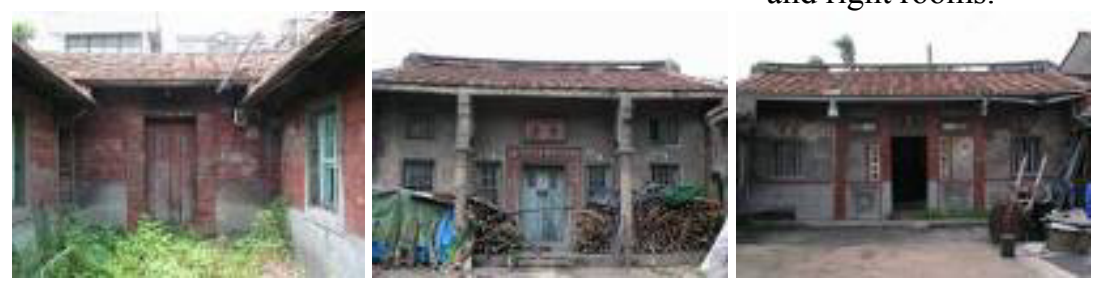

3-room 1-storey 3-sided 3-room 11/2-storey 3-sided 5-room 1-storey 3-sided 
In the early days the folk residence in the woven bamboo structure was limited by the small load-bearing force of bamboo, so "half storey" was hardly found in any room. Gradually, people found that half storey could be a space for storing things or sleeping, and could offer a space for flexible use in the narrow folk residence. Therefore, brick-and-stone load bearing wall was gradually used in folk residence for building the half storey (Figure 5). Later on, with the pressure of population growth, the half storey originally occupying only onethird of a room's area was gradually enlarged to cover the "vault" of the whole room (Figure 6). Under this practice, the façades of the rooms by the two sides had to be divided into upper and lower storeys in order to meet the need of lighting. This is a very distinctive local feature. For the sake of worshipping gods and ancestors, the hall still maintained the one-storey form. Regarding this form, the left and right rooms could be built with independent staircases for walking up and down, or the hall could be built with staircase to reach the half storey, which could be attached with aisles for reaching the left and right rooms (Figure 7). Nevertheless, the aisle of half storey and the construction of staircase still had to stick to the taboo that they could not be built above the table of sacrificial offering and had to be built in front part of the hall.

With the increase of height of the buildings, the construction materials were also changed from laogu stones to brick-and-stone mixed structure, brick structure or strengthened brick structure. For the evolution up to this stage, the hall was in one-storey form, and the two-storey and one-and-half-storey courtyard houses gradually replaced the one-storey courtyard houses, and became the mainstream of courtyard house buildings in Hongmao Harbour. This new form of building has dense regional characteristics in the coastal fishing village of Kaohsiung area. Around the 1960s, two-storey courtyard houses appeared in Hongmao Harbour. Under the taboo that "nothing is allowed to stay above god," the gods' hall was moved to the second floor, and the first floor was for the use of a sitting room. The overall outlook and space were divided by storeys (Figure 8).

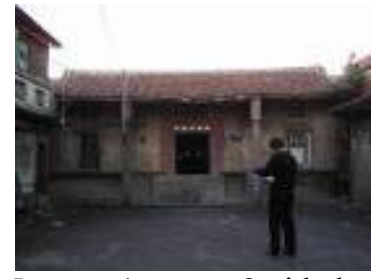

5-room 1-storey 3-sided

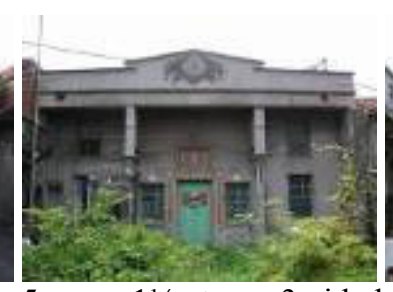

5-room 1/2-storey 3 -sided

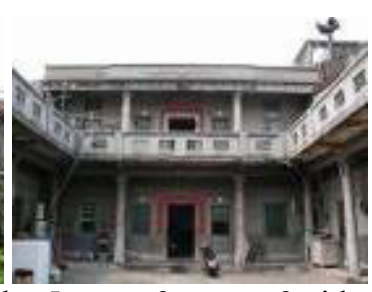

5-room 2-storey 3-sided

Figure 8: Kinds and evolution of courtyard houses of Hongmao Harbour.

\subsubsection{Evolution of structural forms}

In the early days the woven bamboo frame structure is the most common form of courtyard house in Hongmao Harbour. The layout of its plane figure is one dragon. Some of the structures of courtyard houses are found to be formed by three bamboo frames. To match the single-body assembling way of bamboo 
frames, the roofs of the large house and the left and right chambers are not connected, presenting single outlays independently. The life cycle of a bamboo framed building is about 20 years. During the time of reconstruction, in consideration of the economic situation, the treasuring of the existing things and the high mobility of bamboo framed buildings, it was common to see these practices, the reconstruction of large houses, changing the location or direction of large house, and cutting part of the bamboo legs for turning to be a chamber.

Later on, as the economic situation of the residents turned better, there was the digging of laogu stones in the neighbouring forest and the establishment of a brick making kiln. The stronger brick-and-stone load-bearing walls gradually replaced the column legs, and became the mainstream of construction for folk residence. In terms of the categories, the structures are categorized according to the different materials, including the $\operatorname{lag} u$ stone structure, brick-and-stone mixed structure and brick structure. In terms of the layout of plane figure, the woven bamboo frame layout of folk residence still remained. But the roof was changed to be built by wooden pillars, so the dimension of space was greater than the bamboo framed buildings. Besides, regarding the folk residence in brick-and-stone mixed structure, since the aisle between the large house and the chambers began to be covered by roof, thus adding more indoor space for use. This was different from the independent single bodies of the bamboo framed buildings. In addition, the construction of large house and chambers were usually not completed for once, so the connection between the roofs of large house and chambers were found to adopt unique ways being different from the connection in other places. The connection might be linked, or separated. The types were much diversified. All these development reflected the process of gradual growth and modification of the large house and chambers in the settlements of Hongmao Harbour.

At the same time, improvement or the ways of extending the life of bamboo framed buildings also appeared. The lower part of bamboo frame was changed to be built by bricks or laogu stones, decreasing moisture at the bamboo legs. Another way was to lay brick outside the bamboo-framed mud wall, so as to avoid the splashing of rain water. The most effective example was the covering of laogu stones on the original bamboo frame. The supporting pillar structure of the original bamboo frame was replaced by the laogu stone wall. This change was commonly found on the gables by the two sides. Part of the examples are also found to have the façade wall reconstructed. The building at No. 211, Haishan $3^{\text {rd }}$ Road is just the example. The disadvantage of this protective reconstruction and improvement for the bamboo frame is also a distinctive feature of the folk residence of Hongmao Harbour.

\subsection{Decline and disappearance of courtyard houses in Hongmao Harbour}

Ever since the courtyard houses turned to be two-storey form in the 1960s, the courtyard house building had no subsequent development, and the construction activities of courtyard house gradually stopped. Besides, under the residential pressure caused by population growth, effects of construction technology and the out-dated patterns of buildings, the original courtyard houses were successively 
demolished and reconstructed to be long narrow houses, or appeared to be single buildings, or two buildings facing each other. Besides, with the appearance of commercial behaviours, the façade along the street became more and more prosperous, and street houses were constructed.

\section{Conclusions: Evolution of the form of folk residence of Hongmao Harbour and the factors affecting the evolution}

Hongmao Harbour is a settlement formed by the basic units of courtyard houses. The courtyard houses are distributed by the eastern and western sides of Haishan road, lying in southwestern direction and facing the northeast eastern direction. After the Second World War, the inheritance system and the change of construction technology made the land subdivided. In addition, there was a greater need of space with the growth of population. Many courtyard houses were successively demolished. Later on, due to the implementation of the policy of prohibited construction, a large number of corrugated houses were constructed to solve the problem of insufficient living space under the policy. It also formed the unique mixture of the new and old forms and features of the settlement of Hongmao Harbour.

As observed from the evolution of the forms of folk residence of Hongmao Harbour, it can be found that there is an extremely tight relationship among the economic conditions, limitation of land, land subdivision under the inheritance system, and the change of structural forms. Regarding the economic conditions, the poor economic situation made it unavailable for the construction of a courtyard house to be completed for once. The large house and chambers were successively changed and improved to become the complete form of a courtyard house. Meanwhile, the difference of construction times and structural forms induced asymmetrical appearance. Under the limitation of land, the limited development of hinterland and the unavailable horizontal expansion were resulted by a vertical growth, thus forming the one-and-half-storey and twostorey buildings. They even become the extremely distinctive features of Hongmao Harbour. As to the inheritance system, the land was subdivided from square blocks into long narrow blocks. To meet the needs of the distribution of family property and land, the basic three-sided courtyard house units were developed to be long narrow houses. The position of the hall was also changed from the core role of courtyard house to be the aisle between households. The original layout of courtyard house and the lines of settlement were thus collapsed. Furthermore, the changes in structural form and construction materials also facilitated the gradual development of courtyard house buildings towards the two-storey form. It not only met the greater demand of residential space in the settlement of Hongmao Harbour caused by the gradual population growth, but also accomplished the enriched and diversified forms and features of buildings. 
166 Structural Studies, Repairs and Maintenance of Heritage Architecture X

\section{References}

[1] Hung, Wen-hsiung. "Bamboo frame built by the Chinese in Taiwan," Report of the $6^{\text {th }}$ Conference of Reparation Technology of Historical Relics, Council for Cultural Affairs, Executive Yuan, Taipei, 1993.

[2] Chang, Yu-tung, Lin Shih-chao. Foundation Survey, Measurement and Drawing Plan of the Historical Settlements of Hongmao Harbour, Cultural Affairs Bureau of Kaohsiung City Government, Kaohsiung, 2006. 